\title{
Thiourea isosteres as anion receptors and transmembrane transporters $\dagger$
}

\author{
Marco Wenzel, ${ }^{a}$ Mark E. Light ${ }^{a}$ Anthony P. Davis ${ }^{b}$ and Philip A. Gale ${ }^{* a}$ \\ Received (in $X X X, X X X)$ Xth $X X X X X X X X X 20 X X$, Accepted Xth $X X X X X X X X X 20 X X$ \\ DOI: $10.1039 / b 000000 x$
}

\begin{abstract}
5 Compounds containing cyanoguanidine and 3-amino-1,2,4benzothiadiazine-1,1-dioxide have been studied as anion receptors and transporters. Significant affinity for oxo-anions was observed in organic solution and the receptors were found to function as transmembrane chloride/nitrate 10 antiporters with transport rates enhanced in the presence of valinomycin $-\mathbf{K}^{+}$complex.
\end{abstract}

The transport of anions across lipid bilayers is vital to a number of important biological processes. Dysregulation of passive chloride transport causes a number of diseases including cystic 15 fibrosis. There is therefore intense current interest in developing synthetic transmembrane transporters to act as potential future therapeutic substitutes for naturally occurring ion channels (and as tools for the study of anion transport processes in cells). ${ }^{1}$ Recent work within our group has highlighted the anion transport 20 capabilities of a variety of molecules ${ }^{2}$ including a series of simple thioureas. ${ }^{3,4}$ However, some thiocarbamates and thioureas have been found to be toxic, ${ }^{5}$ with the mechanism of toxicity not fully understood. ${ }^{6}$ Non-classical isosteres such as substituted guanidine ligands $\mathbf{1}$ and $\mathbf{2}$, offer a promising non-toxic alternative to 25 thioureas. In particular cyanoguanidine has comparable physical properties to thiourea (e.g. $\mathrm{pK}_{\mathrm{a}}: 15$ (thiourea) and 14 (cyanoguanidine); hydrophobic partition P: 0.09 (thiourea) and 0.07 (cyanoguanidine); $\mathrm{C}-\mathrm{N}$ bond lengths: $1.34 \AA$ both thiourea and cyanoguanidine; N-C-N angle: $119^{\circ}$ (thiourea) and $124^{\circ}$ 30 (cyanoguanidine), respectively) and is present in the drug cimetidine. ${ }^{7}$ However, $N, N^{\prime}, N^{\prime}$ '-trisubstituted guanidine groups often adopt a trans orientation of the two hydrogen atoms of the guanidine subunit and hence are not preorganised to bind anionic guests (Fig. 1). ${ }^{8}$ Alternative conformationally locked systems 35 containing parallel hydrogen bond donors based upon 3-amino1,2,4-benzothiadiazine-1,1-dioxide (e.g. 3). These groups have been synthesised previously ${ }^{9}$ but have not yet applied to anion recognition. As both cyanoguanidines and derivatives of 3amino-1,2,4-benzothiadiazine-1,1-dioxide are known to be 40 compatible with biological systems ${ }^{7,9-11}$ we decided to synthesise some potential anion receptors 1-3 containing these groups and study their lipid bilayer transport properties compared to simple thiourea 4.

The receptors 1-4 were synthesised by modifications to literature ${ }_{45}$ procedures (see ESI $\dagger$ ). ${ }^{4,11,12}$ Crystal structures of the both cyanoguanidine receptors $\mathbf{1}$ and $\mathbf{2}$ show the compounds adopt the trans orientation of the two hydrogen atoms of the guanidine subunit in the solid state (Fig. 1a and Fig. 1b). Strong intermolecular alternating $\mathrm{N}-\mathrm{H} \cdots \mathrm{N}$ hydrogen bonds $(\mathrm{N} \cdots \mathrm{N}$ 50 distances of 2.932(4) and 2.950(4) $\AA$ in $\mathbf{1}$ and 2.857(3) $\AA$ in 2, respectively, Table S1 ESI $\dagger$ ) between the cyanoguanidine $\mathrm{C} \equiv \mathrm{N}-$ group and the cis-orientated $\mathrm{N}-\mathrm{H}$ group of two ligands support the present arrangement. In addition weaker $\mathrm{N}-\mathrm{H} \cdots \mathrm{N}$ hydrogen bonds $(\mathrm{N} \cdots \mathrm{N}$ distance of 3.122(3) and 3.127(3) $\AA$ in $\mathbf{1}$ and ${ }_{55} 3.013(3) \AA$ in 2 , respectively) are formed between the cyanoguanidine $\mathrm{C} \equiv \mathrm{N}$ - group and the trans-orientated $\mathrm{N}-\mathrm{H}$ group to link the dimer. This results in 2-D network of hydrogen bonds in the crystal. In contradistinction to these results, the cisorientation is observed for the thiourea group in the crystal 60 structure of 4 (Fig. S1 ESI†े).<smiles>CNC(=NC#N)Nc1ccccc1</smiles><smiles>CCCCCCCCCCNC(=S)Nc1ccccc1</smiles>

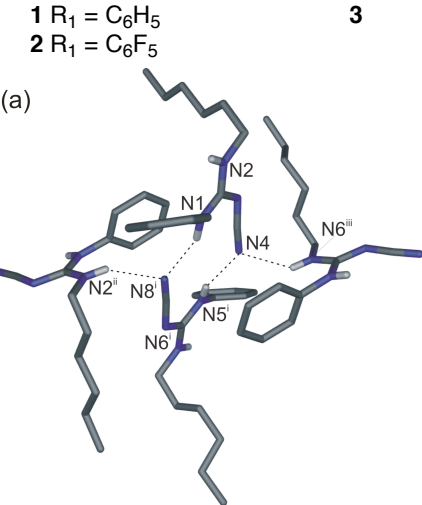

(b)

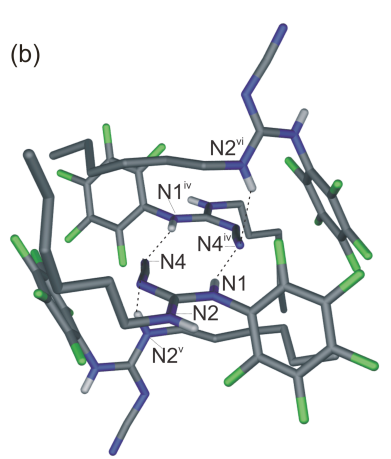

Fig. 1 Schematic draw of the crystal structure (a) of $\mathbf{1}$ and (b) of 2, selected atom labels, dotted lines represent hydrogen bonds, non-interacting hydrogen atoms omitted for clarity, for $\mathbf{2}$ major occupied species only, Symmetry codes: $\mathrm{i}=1+\mathrm{x}, \mathrm{y}, \mathrm{z}$; ii $=$ ${ }_{65} 1 / 2+x, 3 / 2-y,-z ;$ iii $=-1 / 2+x, 1 / 2-y,-z ;$ iv $=2-x, 1-y, 1-z ; v=-2-x,-$ $1 / 2+y, 1 / 2-z ; v i=2-x,-1 / 2+y, 1 / 2-z$.

Proton NMR titration techniques were used to measure the stability of the receptor : anion complexes. Job plot analyses 70 indicate a 1:1 binding mode for all the receptors (see ESI $\dagger$ ). Stability constants for the formed complexes were determined using the EQNMR computer program. ${ }^{13}$ Proton NMR titrations were conducted in DMSO- $d_{6} / 0.5 \%$ water solutions with tetrabutylammonium anion salts. The results show that in all 75 cases the receptors bind sulfate strongly with $\log K_{a}$ of 3.59 and 
3.62 for receptor $\mathbf{1}$ and $\mathbf{4}$ and $\log K_{a},>4$ for receptors $\mathbf{2}$ and $\mathbf{3}$ Stability constants with chloride, dihydrogen phosphate, benzoate and acetate were also determined (Table 1). Addition of tetrabutylammonium nitrate under these conditions did not cause 5 a shift of the receptors' proton resonances.

Detailed examinations of the titration spectra of receptor $\mathbf{1}$ show a significant difference in the NH-proton shift upon the titration with sulfate and chloride (Fig. 2). The stack plot shows the simultaneous shift of the NH resonances by 3.3 and $3.5 \mathrm{ppm}$ 10 upon the addition of sulfate. This is evidence that leads us to suggest that the receptor is conformationally flexible in solution and in the presence of sulfate both $\mathrm{NH}$ groups are oriented towards the anion. On the other hand, the weaker binding of chloride results in a significant shift of only one proton signal by $150.3 \mathrm{ppm}$ in the presence of excess chloride, evidence to suggest that anion interacts with only a single $\mathrm{NH}$ group in this case.

Table 1 Stability constants $\log K$ of 1:1 complexes in DMSO- $d_{6} / \mathrm{H}_{2} \mathrm{O} 0.5$ $\%, 25^{\circ} \mathrm{C}$. Errors are estimated to be $<15 \%$.

\begin{tabular}{|c|c|c|c|c|}
\hline anion & $\mathbf{1}$ & $\mathbf{2}$ & $\mathbf{3}$ & $\mathbf{4}$ \\
\hline $\mathrm{SO}_{4}{ }^{2-}$ & 3.59 & $>4$ & $>4$ & $3.61^{\text {a) }}$ \\
\hline $\mathrm{H}_{2} \mathrm{PO}_{4}^{-}$ & 2.37 & $-{ }^{-}$ & 3.74 & 2.42 \\
\hline $\mathrm{Cl}^{-}$ & $0.56^{\text {a) }}$ & $\left.-^{-}\right)$ & 1.56 & $-^{\text {c) }}$ \\
\hline $\mathrm{PhCOO}^{-}$ & 2.03 & $-^{-}$ & 3.70 & 2.32 \\
\hline $\mathrm{CH}_{3} \mathrm{COO}^{-}$ & 2.51 & 3.23 & 3.91 & 2.64 \\
\hline
\end{tabular}

20 a) error $20 \%$ b) broadened NMR resonances, c) small shifts - could not be fitted to a $1: 1$ or $1: 2$ binding model
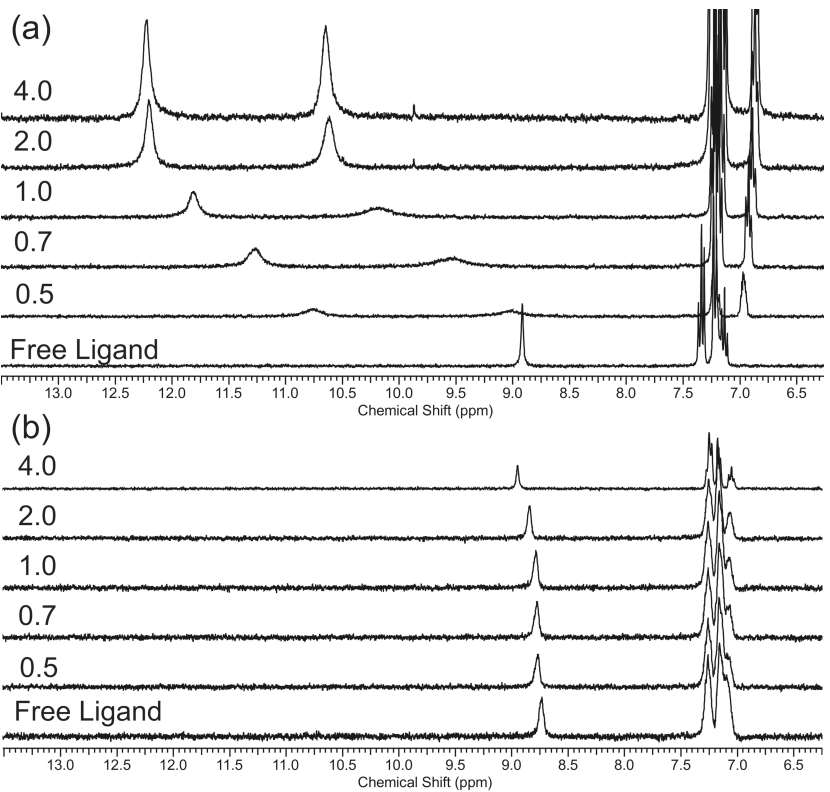

Fig. 2 NMR titrations of compound 1 with a) $\mathrm{TBA}_{2} \cdot \mathrm{SO}_{4}$ (top) and b) ${ }_{25} \mathrm{TBA} \cdot \mathrm{Cl}$ (bottom).

In order to study the chloride transport properties of compounds 1-3 and the control compound $\mathbf{4}$ we prepared a series of unilamellar 1-palmitoyl-2-oleoylphosphatidylcholine (POPC) 30 vesicles loaded with $\mathrm{KCl}(489 \mathrm{mM})$ and suspended them in an external $\mathrm{KNO}_{3}(489 \mathrm{mM})$ solution using previously reported procedures. $^{6,7}$ A sample of receptor 1-4 (2\% molar carrier to lipid) was added as a DMSO solution and the resultant $\mathrm{Cl}^{-}$efflux monitored using a chloride selective electrode. After $300 \mathrm{~s}$, the
35 vesicles were lysed by addition of detergent and the final reading of the electrode was used to calibrate $100 \%$ release of chloride. The results are shown in Fig. 3 and reveal chloride transport of compounds $\mathbf{1}$ and $\mathbf{3}$ (both $5 \%$ after 270 s). The pentafluorophenyl substituted receptor $\mathbf{2}$ was found to be more active and 40 approaching $29 \%$ release of chloride over the timescale of the experiment. This is comparable to the transport ability of the thiourea receptor 4. The latter shows a chloride efflux of approximately $30 \%$, which is similar to the activity of a previously reported phenyl thiourea receptor. ${ }^{4}$

${ }_{45}$ There are a number of potential mechanisms that could be responsible for releasing chloride under the conditions of the experiment. We repeated the transport experiments with sodium rather than potassium salts and found no change in the chloride transport rate (evidence against a $\mathrm{K}^{+} / \mathrm{Cl}^{-}$co-transport mechanism). ${ }_{50}$ The transport experiments were repeated under similar conditions but with sulfate as the extravesicular anion. Under these conditions no chloride transport was observed. This is evidence that leads us to suggest that $\mathrm{Cl}^{-} / \mathrm{NO}_{3}{ }^{-}$antiport is the predominant mechanism responsible for the release of chloride from the 55 vesicles. Further studies in POPC/cholesterol $70: 30$ vesicles showed a reduction in chloride transport rate consistent with the compounds 1-4 functioning as discrete molecular carriers and not as channels (Fig. S2 - S5 ESI†).

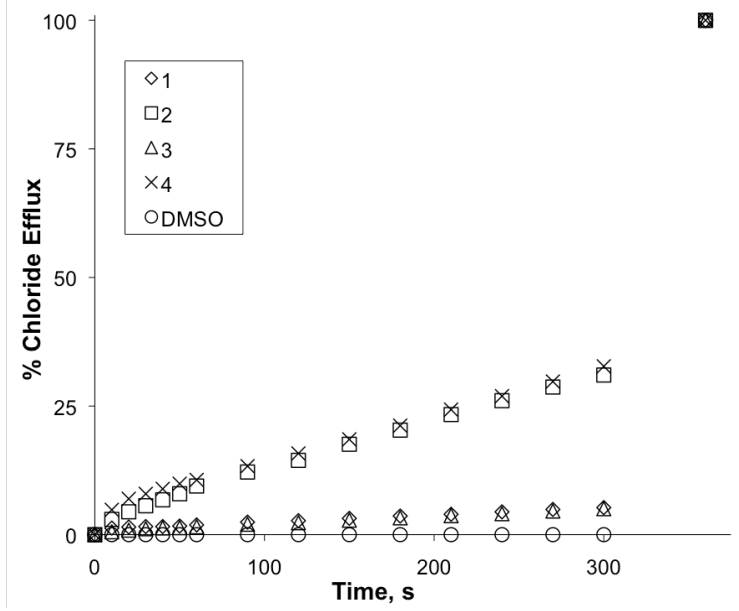

Fig. 3 Chloride efflux promoted by 0.02 molar equiv. of receptors 1-4 from unilamellar POPC vesicles loaded with $489 \mathrm{mM} \mathrm{KCl}$ buffered to $\mathrm{pH}$ 7.2 with sodium phosphate salts. The vesicles were dispersed in $489 \mathrm{mM}$ $\mathrm{KNO}_{3}$ buffered to $\mathrm{pH} 7.2$ with $5 \mathrm{mM}$ sodium phosphate salts. At the end 65 of the experiment, detergent was added to lyse the vesicles and calibrate the ISE to $100 \%$ chloride release. Each point represents the average of three trials.

We then repeated these experiments in the presence of the potassium ionophore valinomycin. The same experimental 70 conditions were used, namely $\mathrm{KCl}(489 \mathrm{mM})$ loaded vesicles suspended in an external $\mathrm{KNO}_{3}(489 \mathrm{mM})$ solution. The results are shown in Fig. 4 and reveal an enhancement in chloride transport when both valinomycin and one of the receptors 1-4 is present. For example a total chloride efflux of $58 \%$ was observed 75 for $\mathbf{2}$ and valinomycin present together compared to $29 \%$ and 5 $\%$ in the presence of either receptor alone in the previous experiment. A similar result was obtained with compound $\mathbf{4}$, namely an enhancement from $30 \%$ in absence of valinomycin to $56 \%$ in the present of both, 4 and valinomycin. The chloride 80 transport for $\mathbf{1}$ and $\mathbf{3}$ is increased from $5 \%$ to $23 \%$ if 
valinomycin is added in an equimolar amount. The chloride efflux for the receptors 1-4 at $270 \mathrm{~s}$ in the absence and presence of valinomycin are given in Table 2. As no potassium gradient is present, the enhancement observed may be caused by the 5 presence of valinomycin bound potassium cations in the membrane possibly either enhancing extraction of the anions from the aqueous phase into the membrane or stabilizing the receptor bound anion complexes in the lipid bilayer.

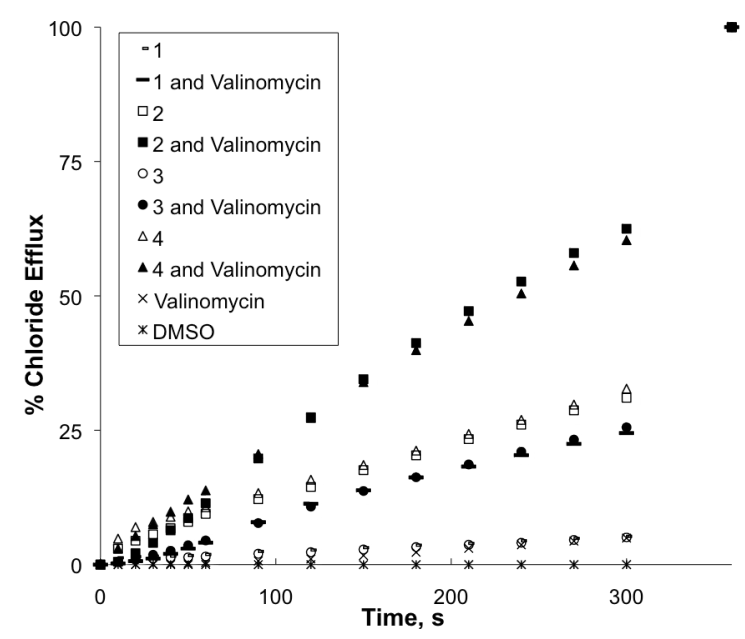

10 Fig. 4 Chloride efflux promoted by 0.02 molar equiv. of receptors 1-4 in the presence and absence of valinomycin $(0.02$ molar equiv.) from unilamellar POPC vesicles loaded with $489 \mathrm{mM} \mathrm{KCl}$ buffered to $\mathrm{pH} 7.2$ with sodium phosphate salts. The vesicles were dispersed in $489 \mathrm{mM}$ $\mathrm{KNO}_{3}$ buffered to $\mathrm{pH} 7.2$ with $5 \mathrm{mM}$ sodium phosphate salts. At the end 15 of the experiment, detergent was added to lyse the vesicles and calibrate the ISE to $100 \%$ chloride release. Each point represents the average of three trials.

Table 2 Chloride efflux (\%) promoted by 0.02 molar equiv. of receptors 1-4 in the absence and presence of valinomycin ( 0.02 molar equiv.) from 20 unilamellar POPC vesicles loaded with $489 \mathrm{mM} \mathrm{KCl}$ buffered to $\mathrm{pH} 7.2$ with sodium phosphate salts after $270 \mathrm{~s}$. The vesicles were dispersed in $489 \mathrm{mM} \mathrm{KNO}_{3}$ buffered to $\mathrm{pH} 7.2$ with $5 \mathrm{mM}$ sodium phosphate salts.

\begin{tabular}{|c|c|c|c|c|}
\hline & \multicolumn{4}{|c|}{ Chloride efflux at 270 s (\%) } \\
\hline & $\mathbf{1}$ & $\mathbf{2}$ & $\mathbf{3}$ & $\mathbf{4}$ \\
\hline Absence of valinomycin & 5 & 29 & 5 & 30 \\
\hline Presence of valinomycin & 23 & 58 & 23 & 56 \\
\hline
\end{tabular}

\section{Conclusions}

This work has demonstrated that thiourea isosteres such as 25 functionalised cyanoguanidines and the hexyl derivative of 3amino-1,2,4-benzothiadiazine-1,1-dioxide are capable of binding and transporting anions. Compound 2 shows transport activity which is similar to thiourea derivative $\mathbf{4}$ whilst the transport properties of all the compounds are enhanced in the presence of 30 valinomycin- $\mathrm{K}^{+}$. These initial studies with simple systems suggest that these hydrogen-bonding motifs may be optimised for anion complexation and transport. We are currently working to incorporate these new anion transport hydrogen bonding motifs into more efficient transporters for chloride and other anions.

\section{Acknowledgements}

We thank the EPSRC for funding and for use of the crystallographic facilities at the University of Southampton. PAG thanks JSPS for an invitation fellowship to the University of
40 Kyushu.

\section{Notes and references}

${ }^{a}$ Chemistry, University of Southampton, Southampton, SO17 1BJ, UK. Email: philip.gale@soton.ac.uk; Fax: +44 (0)23 8059 6805; Tel:+ 44 (0)2380593332

${ }_{45}{ }^{b}$ School of Chemistry, University of Bristol, Cantock's Close, Bristol, BS8 1TS, UK.E-mail: anthony.davis@bristol.ac.uk

$\dagger$ Electronic Supplementary Information (ESI) available: Ligand synthesis, additional crystallogrphy, transport and NMR studies. CCDC 821666 - 821668. See DOI: $10.1039 /$ b000000x/

$50 \$$ Crystal data for 1: $\mathrm{C}_{14} \mathrm{H}_{20} \mathrm{~N}_{4}, \mathrm{M}=244.34$, orthorhombic, $\mathrm{a}=10.2071(2)$ $\AA, \mathrm{b}=11.2105(3) \AA, \mathrm{c}=24.2602(6) \AA, \mathrm{V}=2776.01(11) \AA^{3}, \mathrm{~T}=120 \mathrm{~K}$, $\mathrm{P} 2{ }_{1} 2_{1} 2_{1}$ (no. 19), $\mathrm{Z}=8,27023$ reflections measured, 3585 unique $\left(\mathrm{R}_{\text {int }}=\right.$ 0.0775 ) of which 3585 were used in the calculations, $R_{1}=0.0546$ (2806 with $F>2 \sigma(F)$ ), for this light atom structure Friedel opposites were 55 merged and delta f', value for all elements set to zero.

2: Cystal data for $\mathrm{C}_{14} \mathrm{H}_{15} \mathrm{~N}_{4} \mathrm{~F}_{5}, \mathrm{M}=334.30$, monoclinic, $\mathrm{a}=13.6862(9) \AA$, $\mathrm{b}=10.6669(7) \AA, \mathrm{c}=11.3955(7) \AA, \beta=109.57(4), \mathrm{V}=1567.52(17) \AA^{3}$, $\mathrm{T}=120 \mathrm{~K}, \mathrm{P} 21 / \mathrm{c}$ (no. 14), $\mathrm{Z}=4,25328$ reflections measured, 3614 unique $\left(R_{\text {int }}=0.0916\right)$ of which 3614 were used in the calculations, $R_{1}=$ ${ }_{60} 0.0706(2773$ with $\mathrm{F}>2 \sigma(\mathrm{F}))$, carbon 12 and 13 of the alkyl chain in 2 are disordered over 2 positions with an occupancy of 0.5 each.

1 P. A. Gale, Acc. Chem. Res., 2011, 44, 216-226; C.J.E. Haynes and P.A. Gale, Chem. Commun. 2011, DOI: 10.1039/c1cc12061a; A.P.

65 Davis, D. N. Sheppard and B. D. Smith, Chem. Soc. Rev., 2007, 36, 348-357; J. T. Davis, O. Okunola and R. Quesada, Chem. Soc. Rev., 2010, 39, 3843-3862.

2 J. T. Davis, P. A. Gale, O. A. Okunola, P. Prados, J. C. IglesiasSanchez, T. Torroba and R. Quesada, Nat Chem, 2009, 1, 138-144; P.

70 A. Gale, C. C. Tong, C. J. E. Haynes, O. Adeosun, D. E. Gross, E. Karnas, E. M. Sedenberg, R. Quesada and J. L. Sessler, J. Am. Chem. Soc., 2010, 132, 3240-3241.

3 N. Busschaert, P. A. Gale, C. J. E. Haynes, M. E. Light, S. J. Moore, C. C. Tong, J. T. Davis and J. W. A. Harrell, Chem. Commun, 2010, 46, 6252-6254.

4 N. J. Andrews, C. J. E. Haynes, M. E. Light, S. J. Moore, C. C. Tong, J. T. Davis, W. A. Harrell Jr and P. A. Gale, Chem. Sci., 2010, 2, 256260

5 P. B. Smith and C. Crespi, Biochem. Pharmacol., 2002, 63, 1941-

80 1948; R. C. A. Onderwater, J. N. M. Commandeur, E. J. Groot, A. Sitters, W. M. P. B. Menge and N. P. E. Vermeulen, Toxicology, 1998, 125, 117-129.

6 S. A. Svarovsky, R. H. Simoyi and S. V. Makarov, J. Phys. Chem. B, 2001, 105, 12634-12643.

857 G. J. Durant, J. C. Emmett, C. R. Ganellin, P. D. Miles, M. E. Parsons, H. D. Prain and G. R. White, J. Med. Chem., 1977, 20, 901906.

8 C. G. McCarty, R. V. Chastain and D. M. Wieland, J. Chem. Soc. D., 1971, 198-199.

909 S. Boverie, M.-H. Antoine, F. Somers, B. Becker, S. Sebille, R. Ouedraogo, S. Counerotte, B. Pirotte, P. Lebrun and P. de Tullio, J. Med. Chem., 2005, 48, 3492-3503.

10 P. Lebrun, B. Becker, N. Morel, P. Ghisdal, M.-H. Antoine, P. de Tullio and B. Pirotte, Biochem. Pharmacol., 2008, 75, 468-475; P. d.

95 Tullio, L. Dupont, P. Francotte, S. Counerotte, P. Lebrun and B. Pirotte, J. Med. Chem., 2006, 49, 6779-6788; B. Pirotte, P. de Tullio, Q.-A. Nguyen, F. Somers, P. Fraikin, X. Florence, P. Wahl, J. B. Hansen and P. Lebrun, J. Med. Chem., 2010, 53, 147-154.

11 P. de Tullio, S. Boverie, B. Becker, M.-H. Antoine, Q.-A. Nguyen, P. 100 Francotte, S. Counerotte, S. Sebille, B. Pirotte and P. Lebrun, J. Med. Chem., 2005, 48, 4990-5000.

12 L. Novak, M. Hanania, P. Kovacs, C. E. Kovacs, P. Kolonits and C. Szantay, Synth. Commun., 1999, 29, 1757-1766; P. d. Tullio, B. Pirotte, F. Somers, S. Boverie, F. Lacan and J. Delarge, Tetrahedron, 1998, 54, 4935-4942.

13 M. J. Hynes, J. Chem. Soc., Dalton Trans, 1993, 311-312. 